\title{
Formation of social initiative of students by means of coaching technology
}

\author{
L.V. Savchenko ${ }^{1 *}$, E.V. Vovk ${ }^{2}$, and O.V. Pravdyuk ${ }^{3}$ \\ ${ }^{1}$ V.I. Vernadsky Crimean Federal University, Simferopol, Russia \\ ${ }^{2}$ V.I. Vernadsky Crimean Federal University, Simferopol, Russia \\ ${ }^{3}$ Sevastopol Branch of Moscow State University after M.V. Lomonosov, Sevastopol, Russia
}

\begin{abstract}
This article reveals the method of developing of social initiative with the help of coaching technology. The article describes an empirical study conducted by the authors that demonstrates the effectiveness of using coaching technology as an innovative method of developing students' social initiative. The authors confirm the urgency of the study, focusing on the fact that the content of the requirements imposed on a person by the social environment has changed, and in modern Russia, university graduates should be independent and their work which is carried out within the framework of the program for the development of youth social initiative is effective.
\end{abstract}

\section{A problem statement}

The urgency of the study depends on the growing demand for the personal and professional characteristics of future university graduates. In the modern socio-cultural situation, the key message of the trajectory of education at the stage of professional training of specialists is not only the qualitative formation of basic knowledge and disciplined skills of young people, but also the development of students' personal qualities, in which the federal state educational standards, which have come into force, proclaim a systematic approach to activities that ensures the formation of social initiative and a positive personality of students in the process of getting higher education.

Since one of the basic requirements of human life is the need for meaningful, morally and socially useful changes in the surrounding reality, the priority of the formation of a future specialist is his development. Modern society needs young specialists who are able to make their own choices and decisions that are profitable for society, to implement them effectively and to be responsible for the future development of the country. The manifestation of social initiative, encouraged to implement a socially useful idea, to change the surrounding reality constructively, determines the social well-being of the student's personality and is an important quality of future profession.

In modern realities, the formation of social initiative, which is the most important condition for the development of an individual's career, corresponds to the standards and is confirmed by the normative documents regulating the functioning of the education system.

* Corresponding author: prof-ped.gpa@mail.ru 
Social initiative is viewed as the most important resource for socio-economic and social development. Moreover, not only at the national, but also at the international level, the importance of social initiative of young people is demonstrated, since it is analyzed from the point of view of the value approach within the framework of modern citizenship [1].

Young people are the most important resource for future social changes and national development; they are focused on achieving their own, group and social goals, and have the potential to take an active part in socially useful activities.

Successful promotion and self-realization in the social and professional environment are facilitated by the active use of one of the innovative forms of educational technology coaching technology in vocational training. The use of coaching methods corresponds to the goals of modernization and humanization of the system of specialized education and allows you to create an educational space for personal development, built according to the logic of personalized learning and contributing to self-determination, self-realization and self-improvement of students.

Throughout the development of science in the country and abroad, philosophers, teachers, psychologists, sociologists, political scientists and representatives of other fields of science have shown considerable interest in studying the problem of initiative.

In pedagogical science, since the $60 \mathrm{~s}$ of the twentieth century, there has been a particularly intense research attention to this direction, which was reflected in the creation of a number of scientific works. In particular, there are works devoted to the formation of social initiative of the younger generation through the implementation of socially useful activities and participation in pioneer and Young Commuinist League organizations.

The review of psychological and pedagogical research of recent years also shows that nowadays the topic of social initiative will continue to remain one of the most urgent and important. According to V.E. Pyrkov, recently there has been a special interest in pedagogy, which is searching for theoretical and practical ways of solving the problem of developing individual social initiative [2].

The term "initiative" itself comes from the Latin "initium", which literally means "beginning". Being interdisciplinary, this concept has become generally accepted in the humanitarian field of science and has become the subject of research by philosophers, psychologists, sociologists and educators.

The study of the main substantive aspects of the initiative was noted in the works of ancient Greek philosophers (Plato, Aristotle) and has a long history in the development of sciences. D. Locke, who believed that initiative is important for success, at the same time saw the main motivation for initiative - the personal interests of the individual [3].

In the work of I.A. Pankratova the importance of developing initiative among the younger generation is emphasized. According to the researcher, the origin and formation of initiative lies in the desire of individuals to perform actions actively, in the presence of a wide variety of interests, in the ability to exercise self-activity and overcome difficulties and obstacles [4].

The native pedagogical science is characterized by a comprehensive study of the problem of initiative in the context of considering games, socially useful activities and individual initiative as a key condition for the emergence and development of initiative. The retrospective analysis of scientific literature shows that, in general, an initiative is a kind of individual action performed in an original way or in the name of a fundamentally new idea or goal of himself and / or society [2].

At the same time it is generally accepted in modern pedagogical science that the concept of initiative should include not only the procedural aspects of the actual implementation of a new action, but also the initial phase of action.

The modern researcher N.M. Zyryanova emphasizes the importance of presenting initiative in three forms (manifestations): 
- proposals-initiatives;

- take the initiative into your own hands;

- active position [5].

Such an approach allows one to take into account the external activity of the individual in internal relationships and transitions to each other, and vice versa, which, of course, is an important point in any psychological and pedagogical research.

In the modern comprehension, the concept of "active" implies the following meanings:

1) To begin with the internal motivation of a person for carrying out new types and forms of activity.

2) The internal motivation to search for new ways to solve the problem by going beyond the specified conditions and limits.

3) To perform leadership roles in specific actions.

4) The ability and willingness of the individual to carry out positive actions.

5) The desire to promote and implement any innovative ideas, methods for solving specific problems in entrepreneurship materially.

6) The form of personal (creative) self-expression, demonstration of activities related to someone, cognition, communication and mechanisms for stimulating activity.

7) One of the forms of activity as the main reason for starting an activity. [6].

8) Some form of expression of personal needs, the way it interacts with social reality

The analysis of pedagogical literature shows that initiative is a specific ability of a person, which includes a tendency to carry out any actions independently and in an active way, to realize personal initiative in one's own activity.

Foreign scientific literature reflects the understanding that initiative is a personality trait, including cognitive and motivational aspects, and determines the implementation of hyper situational intellectual activity in order to come up with an innovative idea and carry out activities for the practical application of the idea, at the process of which there is a personal change and the author's transformation of the surrounding reality [7].

In modern society, there is a need for a person who is constantly striving for professional and personal self-development, which means the understanding and expressing of one's abilities and talents with the use of new tools of psychological correction and psychological consulting, which will be focused not on the problem, but on its solution.

A new technique of psychological support can be called coaching. It originated in the work of psychological consulting of athletes, and then for a long time had been developing into the technique of organizational and business consulting and as a technique for developing talent.

According to the "English-Russian Dictionary", the concept of "coaching" means "training, tutoring, preparation for an exam or competition"; in the Concise Oxford Dictionary, "coaching" means "to direct, to motivate, to teach".

The term "coach" was introduced into practice by John Whitmore and was understood by him as "co-realization", "help" [8]. Modern researchers believe that the origins of coaching are the Socratic method of dialogue, the psychoanalytic theory of Z. Freud, A. Maslow, K. Rogers, the works of D. Goleman, the methodology of T. Galvi.

In a relatively short period of time, the theory of coaching spread quickly throughout the world and today it continues to be successfully applied in business, psychology and management. Today, coaching has become the most common in the United States and Japan. According to the study carried out in Russia, the market for coaches in the country is developing dynamically thanks to the professional coaching community and schools that train coaches according to programs admitted by the ICF and other international communities. IFC member coaches acknowledge that the results achieved "are the result of 
the client's intentions, decisions and actions, reinforced by the coach's efforts and the application of the coaching process" [9].

In coaching the main attention is paid to the current situation and to what actions the participants are willing to take to achieve the desirable state. Therefore, within the framework of solving the problem of forming the student's social initiative, coaching technologies contribute to the increase in self-awareness of an individual as a professional.

\subsection{The objective of the work}

The empirical part of the study of the formation of social initiative of students of the Federal State Autonomous Educational Institution of Higher Education "V.I. Vernadsky Crimean Federal University" consisted of the following stages:

1) The determining of the experiment. At this stage the preliminary diagnostics was carried out.

2) The formative experiment. The direct implementation of the consulting plan aimed at developing social initiative in the experimental group of students.

3) The controlling experiment. After the group consulting, a plan for secondary diagnosis is drawn up for the experimental and control groups of students tested.

The study involved 39 people aged from 23 to 28 years. The average age was 24.5 years. Most of the tested showed interest in the research and let us know that they were involved in the process. The strongest motivation for the respondents was the prospect of getting a diagnosis. The sample was formed to determine the level of formation of students' social initiative.

For carrying out the study, the method of determining the level of development of professional identity was chosen; the method focused on determining the level of individual self-regulation and self-attitude; the methodology "Personal Professional Program".

\section{Results of the research}

The results were processed according to the key of the method. The average level of professional recognition in the experimental and the control groups is divided into the units shown in Table 1.

Table 1. The average level of professional status.

\begin{tabular}{|l|l|l|l|}
\hline № & \multicolumn{1}{|c|}{ The Parameter } & $\begin{array}{c}\text { The Average Value } \\
\text { in the Experimental } \\
\text { Group }\end{array}$ & $\begin{array}{c}\text { The Average Value } \\
\text { in the Control } \\
\text { Group }\end{array}$ \\
\hline 1 & $\begin{array}{l}\text { The level of professional identity in } \\
\text { points }\end{array}$ & $3.4 \pm 1.56$ & $3.2 \pm 1.51$ \\
\hline
\end{tabular}

According to the level of social initiative, the respondents can be divided into 3 categories: students with a lower level of social initiative (0-2 points), students with an average level of social initiative (3-5 points), students with a higher level of social initiative (6-7 points). The average level of development of social initiative, characterized by passive social initiative, included the results of $50 \%$ of the tested in the experimental group and $63 \%$ of the tested in the control group.

A high level of social initiative (15\% of respondents in the experimental group and $11 \%$ of respondents in the control group) showed significant positive social initiative. At the same time a low level of professional identity was observed in almost a third of the experimental and control groups $-35 \%$ and $26 \%$, respectively. It means that most of the respondents know in which direction they want to develop, but they do not have a specific plan of action. 
Taking into consideration that the respondents are the second-year students, that is, those who complete the second stage of vocational training, the presence of an average of $30 \%$ of respondents with low social initiative can become a source of problems for a successful start. The results of calculating two independent samples of the nonparametric standard of U-Mann-Whitney test are shown in Table 2.

Table 2. The results of the comparative analysis of indicators of the level of professional identity in the experimental and control groups.

\begin{tabular}{|l|l|}
\hline U-Mann-Whitney criterion & The level of statistical significance (p) \\
\hline 179 & 0.771 \\
\hline
\end{tabular}

Both groups showed the achieved level of self-esteem - the highest average point was marked on the "self-esteem" scale, and the indicators of self-confidence and self-attitude were also slightly above average. The rest of the indicators in both groups can be defined as average, since they are in the range from 4 to 7 points. In particular, on the scale of "selfguidance", this is an important sign, if not decisive for the self-development of a person, both groups have average values: 6.5 and $6.2 \%$. It means that at the formative stage of the experiment, special attention should be paid to the development of the subject's independence. The general level of self-regulation in both groups can be characterized as average. It means that at the stage of the formation of the experiment, special attention should be paid to the development of the general level of self-regulation, in particular of such components as planning and independence. Based on the results of determining the diagnosis, the following main conclusions can be drawn: there was no statistically significant difference in the analytical indicators of professional identity, social self-attitude and self-regulation of undergraduate students in the experimental and control groups.

In accordance with the research criteria, the following levels of formation of individual social initiative were determined: the level of passive initiative, the level of formal initiative, the level of productive initiative. As you can see from the components of the model, every level has certain characteristics. As an indicator of the passive level of formation of individual social initiative we define the following main characteristics:

- the absence or insufficient development of internal motivation and value orientations for the realization of social needs;

- the vague awareness of their social activities, a minimum amount of unsystematic knowledge in the social sphere.

The typical characteristics of the formal level of initiative are the following aspects: the certain understanding of internal motivation and value orientation of the implementation of social needs; the rudiments of cognitive interest based on the accumulation of basic knowledge about the nature of the social sphere; partial development of superficial social self-development and the ability of average social self-regulation.

The level of productive initiative, formed by social initiative, is characterized by desire, abilities and skills formed during the social activity; positive motivation for the actual implementation of their own social activities; a sufficiently comprehensively developed system of knowledge, comprehensive social self-development and the ability to social selfregulation.

\section{Conclusions}

As a result of the study, the following conclusions were made: 
1. The social initiative of students is a systemic quality of a personality based on the ability to put forward original and meaningful socially useful ideas, disseminate them in the course of independent and responsible activities and implement them in order to achieve self-realization and a constructive shift in the surrounding reality. The substantial components of social initiative are motivational, emotional-volitional, cognitive, active and reflexive components, which determine the level of passive, formal and productive initiative in the quality of student learning.

2. The formation of students' social initiative with the help of coaching methods is a specially organized system of pedagogical influence that stimulates the independent and responsible activity of the individual, aimed at the actual implementation of a socially useful idea, at self-realization and constructive change in the surrounding reality. The process of forming the student's social initiative with the help of coaching technologies is ensured through the implementation of the systemic, personal-active, subjective and environmental approaches and consists of four stages: motivation, cognition, activity and reflexivity.

3. Coaching, as a pedagogical method of forming students' social initiative, is an integral system of principles, forms and means of personal and emotional support, which students receive for the implementation of independent activities aimed at developing their personal and emotional support. The key idea of using coaching technologies in the process of forming social initiative is to understand every student as a unique personality with great potential, which allows them to show their individual initiative independently and creatively and to take responsibility for solving various important social problems.

4. The pedagogical model of the formation of students' social initiative with the help of coaching technologies is an integral scientific and theoretical structure that combines interrelated components (goals, objectives, theories and methods, principles, activity content) and functions (including models aimed at implementation of strategies for the effective formation of students' social initiative in the context of the modern educational space of higher education). The main components of the pedagogical model, which forms the social initiative of students with the help of coaching technologies, are the concepts, content and organization of activities and the analysis of effective blocks.

5. The effectiveness of the process of forming students' social initiative through coaching technologies is ensured by a complex of social and pedagogical conditions: the implementation of social and pedagogical support for the progressive formation of students' social initiative based on the development of the potential of coaching technologies; practical implementation of social initiative to include students at the level of autonomy and social partnership (integration of universities with state and public institutions); the use of social and pedagogical resources of universities and student associations, allowing students to take initiative and choose appropriate ones independently, basing on personal life experience and the specifics of the social structure and social situation of the country.

\section{References}

1. V.A. Romanov, Coaching Technology in Tutoring Support for Educational and Professional Self-Realization of Future Specialists, Izvestia of Tula State University, 3, 427-434 (2016)

2. V.E. Pyrkov, Coaching Approach in Teaching Students of High School as a Technology for the Implementation of Modern Education, 6, 24-29 (2017)

3. J. Locke, Two Treatises on Government, 698 (1988)

4. I.A. Pankratova, Formation of Emotional Competence of Students Using Coaching Technology, Professional Education in Russia and Abroad, 3 (27), 103-111 (2017) 
5. N.M. Zyryanova, Coaching in Teaching Adolescents, Bulletin of Practical Psychology of Education, 1, 46-49 (2017)

6. M. Atkinson, Coaching System Step by Step, 281 (2018)

7. T. Golvey, Working as an Inner Game: Unlocking Personal Potential, 266 (2017)

8. J. Whitmore, Leadership Inner Strength: Coaching as a People Management Method, 309 (2017)

9. O.B. Episheva, What is Pedagogical Technology, School Technologies, 1, 31-36 (2019)

10. L.K. Antsigina, M.V. Kolesnikova, On the Problem of Social Activity of the Individual in Modern Conditions, Education and Culture in the West Siberian Region: History, Prospects and Problems of Interaction, 2, 174-176 (2016)

11. E. Parslow, M. Ray, Coaching in Learning: Practical Methods and Techniques, 204 (2016)

12. C. Rogers, Personal Considerations on Teaching and Learning, 200 (2018)

13. V.A. Romanov, Coaching Technology in Tutoring Support for Educational and Professional Self-Realization of Future Specialists, Izvestia of Tula State University, 3, 427-434 (2016)

14. C. Kaufman, From Clinical to Positive Psychology: My Journey to Coaching (2017)

15. C. Kaufman, A. Scoular, Toward a Positive Psychology of Executive Coaching by, Positive psychology in practice, 1, 287-304 (2018) 